Volume 1, Nomor 2, Maret 2021, hlm 59-67

BEMAS: JURNAL BERMASYARAKAT

p ISSN 27455866 | e ISSN 27457958

\title{
PEMBELAJARAN JARAK JAUH PEMROGRAMAN DASAR MENGGUNAKAN BAHASA C++ UNTUK UMUM: SEBUAH PROGRAM PENGABDIAN KEPADA MASYARAKAT
}

\author{
Ashari Imamuddin ${ }^{1 *}$, Mohamad Anas Sobarnas ${ }^{2}$, Nurkholis ${ }^{3}$ \\ ${ }^{1 * 2,3}$ Program Studi Teknik Informatika, Sekolah Tinggi Teknologi Muhammadiyah Cileungsi, Cileungsi, Bogor, \\ Jawa Barat, Indonesia 16820 \\ Email:*ashari@sttmcileungsi.ac.id, anas@sttmcileungsi.ac.id,nurkholis@sttmcileungsi.ac.id
}

\begin{tabular}{l} 
INFORMASI ARTIKEL \\
\hline Article History: \\
Submission: $11-02-2021$ \\
Revised: 12-03-2021 \\
Accepted: 18-03-2021 \\
* Korespondensi: \\
Ashari Imamuddin \\
ashari@ sttmcileungsi.ac.id
\end{tabular}

INFORMASI ARTIKEL

Submission: 11-02-2021

Revised: 12-03-2021

* Korespondensi:

ashari@sttmcileungsi.ac.id

\begin{abstract}
ABSTRAK
Artikel ini mempresentasikan program pengabdian kepada masyarakat (PkM) berupa pelatihan pemrograman dasar komputer menggunakan bahasa $\mathrm{C}++$ yang ditujukan kepada khalayak yang mempunyai minat dan bakat untuk belajar bahasa ini. Untuk memudahkan proses pembelajaran maka latihan dilakukan dengan lebih banyak studi kasus dan praktik. Publikasi penawaran pembelajaran ini dilakukan melalui media sosial. Saat dibuka kesempatan mengikuti pelatihan ini ada sebanyak sebanyak 46 orang pendaftar. Metode pengabdian yang dilakukan adalah dengan pelatihan secara daring dan dilaksanakan selama hampir 5 (lima) bulan setiap hari Sabtu pukul 10:00-11:30 Wib. Hasil dari program pengabdian ini menunjukkan bahwa sebelum dilakukan pengabdian ini mayoritas peserta tidak pernah mengenal pemrograman komputer dan setelah dilakukan program pelatihan ini dihasilkan 5 orang yang benar-benar menguasai pelajaran yang disampaikan. Selain itu kendala koneksi internet menjadi kendala paling banyak dalam proses pembelajaran secara online ini. Namun begitu, para peserta sangat antusias mengikuti proses pembelajaran sampai akhir dan berminat/tertarik mengikutinya kembali kalau ada pelatihan yang sama atau materi dengan level lebih tinggi. Ada beberapa catatan dari peserta untuk perbaikan dari pelatihan ini yaitu mengenai waktu pelatihan, pentingnya memperbanyak latihan dan mengulang materi serta perlu menggunakan analogi-analogi dalam penyampaian materi.
\end{abstract}

Kata Kunci: Pembelajaran jarak jauh, bahasa pemrograman, C++, studi kasus, PkM, proses belajar.

DISTANCE LEARNING OF FUNDAMENTAL PROGRAMMING USING C++ LANGUAGE FOR THE SOCIETY: A COMMUNITY SERVICE PROGRAM

\begin{tabular}{l} 
ABSTRACT \\
This article presents a community service program (PkM) in the form of \\
basic computer programming training using the $C++$ language aimed at \\
audiences who have an interest and talent for learning this language. To \\
facilitate the learning process, training is carried out with more case \\
studies and practices. The publication of this learning offer is done \\
through social media. When the opportunity was opened to take part in this \\
training, there were as many as 46 applicants. The service method used is \\
an online training and is carried out for almost 5 (five) months every \\
Saturday at 10:00 - 11:30 WIB. The results of this service program show \\
\hline
\end{tabular}


Pembelajaran Jarak Jauh Pemrograman Dasar Menggunakan Bahasa C++ Untuk Umum:

Sebuah Program Pengabdian Kepada Masyarakat

\begin{abstract}
that before this service, the majority of participants had never been familiar with computer programming and after this training program produced 5 people who mastered the lessons presented. Also, internet connection constraints are the most problematic in this online learning process. However, the participants were very enthusiastic about following the learning process until the end and were interested/interested in following it again if there was the same training or material with a higher level. There were several notes from the participants for the improvement of this training, namely regarding the training time, the importance of increasing the number of exercises and repeating the material, and the need to use analogies in the delivery of the material.
\end{abstract}

Keywords: distance learning, programming language, $C++$, case studies, PkM, learning process.

\section{PENDAHULUAN}

Tri Dharma Perguruan tinggi adalah salah satu misi dari perguruan tinggi yang ada di Indonesia. Ia meliputi Pendidikan dan Pengajaran[1]. Penelitian dan pengembangan, dan Pengabdian kepada masyarakat. Sebagai usaha mendukung Tri Dharma Perguruan Tinggi Sekolah Tinggi Teknologi Muhammadiyah Cileungsi mendorong dan mendukung para dosen mengadakan kegiatan pengabdian kepada masyarakat (PkM).

Pada periode terdahulu para dosen telah melakukan kegiatan PkM seperti manajemen pengelolaan website dalam rangka pemberdayaan pelajar Sekolah Menengah Kejuruan Muhammadiyah 2 Cileungsi[2]. Pada kegiatan yang dilaksanakan hari Sabtu setiap pekan dari tanggal 18 Januari sampai dengan 8 Februari 2020 ini para dosen memberikan pelatihan kepada para siswa sekolah tersebut untuk memberdayakan dan meningkatkan kemampuan mereka dalam pengembangan website. Dari kegiatan tersebut $92 \%$ dari para peserta mengaku puas dengan pelatihan tersebut dan 94\% merasa sangat bermanfaat.

Pemrograman merupakan keahlian yang sangat penting dikuasai untuk pengembangan perangkat lunak[3][4] termasuk di dalamnya pengembangan website. kepada para pemuda merupakan sesuatu yang penting dan akan bermanfaat bagi para pemuda sebagai bekal untuk memasuki pasar kerja kelak. Pada periode yang sama para dosen lain juga mengadakan lokakarya penguatan kualitas sumber daya manusia generasi muda dalam menghadapi era industrialisasi. Pada lokakarya ini para dosen memberikan motivasi kepada para pemuda yang mengikuti lokakarya ini dalam rangka meningkatkan kemampuan sumber daya manusia kita agar tidak menjadi penonton di negeri sendiri[5].

Dosen lainnya mengadakan program $\mathrm{PkM}$ dalam rangka optimalisasi pemrograman pada perangkat lunak Trutops V 1.2.1 di PT UVW. Dari kegiatan ini diharapkan dapat memberikan gambaran mengenai efisiensi waktu dalam pembuatan program dengan perangkat lunak Trutops V1.2.1. Dari bahasa pemrograman ini nanti akan diaplikasikan dalam bentuk pelatihan ke Siswa SMK, agar pengetahuan dalam hal pemrograman mesin produksi, supaya saat lulus sekolah nanti bisa langsung diserap oleh dunia industri[6].

Mengingat pemrograman komputer merupakan tahapan penting dalam pembuatan software[7] dan banyak orang yang tertarik belajar bahasa pemrograman maka dilaksanakanlah kegiatan pembelajaran ini untuk khalayak umum. Ditambah lagi dengan banyaknya orang yang ingin belajar pemrograman tetapi tidak tahu harus belajar dari mana.

Dalam program kegiatan PkM ini ditawarkan solusi pembelajaran jarak jauh (distance learning) agar dapat menjangkau banyak orang dan proses pembelajaran dapat dilakukan dari tempat peserta masing-masing tanpa harus mengikuti kelas tatap muka. Pembelajaran dilakukan mulai dari dasar (fundamental) pemrograman. Setiap materi dilengkapi dengan contoh dan studi kasus. Pelaksanaan 
pembelajaran dilakukan dengan perlahan (tidak cepat) mengingat perbedaan kemampuan antar peserta.

Target dari kegiatan ini adalah para peserta memahami bahasa pemrograman $\mathrm{C}++[8]$ dan dapat memecahkan masalah sederhana dalam pemrograman. Pemrograman merupakan hal penting dan merupakan salah satu tahapan dalam pembuatan software atau sistem informasi[9][3][4]. Akhir dari program ini diharapkan para peserta dapat melakukan praktik pembuatan program sederhana.Pada gilirannya program ini mendukung agar Setiap warga negara mendapatkan hak yang sama untuk memperoleh pendidikan yang bermutu."[10] Jadi tujuan dari program ini adalah memberikan pelatihan pemrograman komputer dasar menggunakan $\mathrm{C}++$ secara daring kepada khalayak umum terutama pada pemuda sebagai bekal untuk meningkatkan keahlian di bidang pengembangan software karena pemrograman merupakan salah satu bagian dari pengembangan software komputer[11].

\section{METODE}

Metode program pengabdian kepada masyarakat ini adalah (1) mengumumkan melalui social media, yaitu Facebook, Instagram, dan Whatsapp group. Dengan demikian diharapkan para peserta datang dari berbagai kalangan dan dari banyak wilayah yang tak terbatas tempat; (2) Pembelajaran dilakukan secara daring hal ini mengingat juga keadaan pandemi Covid-19 yang masih melanda negeri ini; (3) Penyampaian materi dilakukan dengan penjelasan secara tutorial dan setiap materi dilanjutkan dengan contoh praktikum yang harus diselesaikan oleh peserta; (4) Setelah peserta menyelesaikan tugasnya maka tutor memeriksanya dan memberikan umpan balik kepada peserta; (5) Di akhir pembelajaran para peserta diberikan tugas kasus yang lebih besar untuk diselesaikan; dan (6) Tutor memeriksa hasil pekerjaan para peserta dan memberikan umpan balik. Secara detail dapat dilihat pada diagram pada gambar 1 .

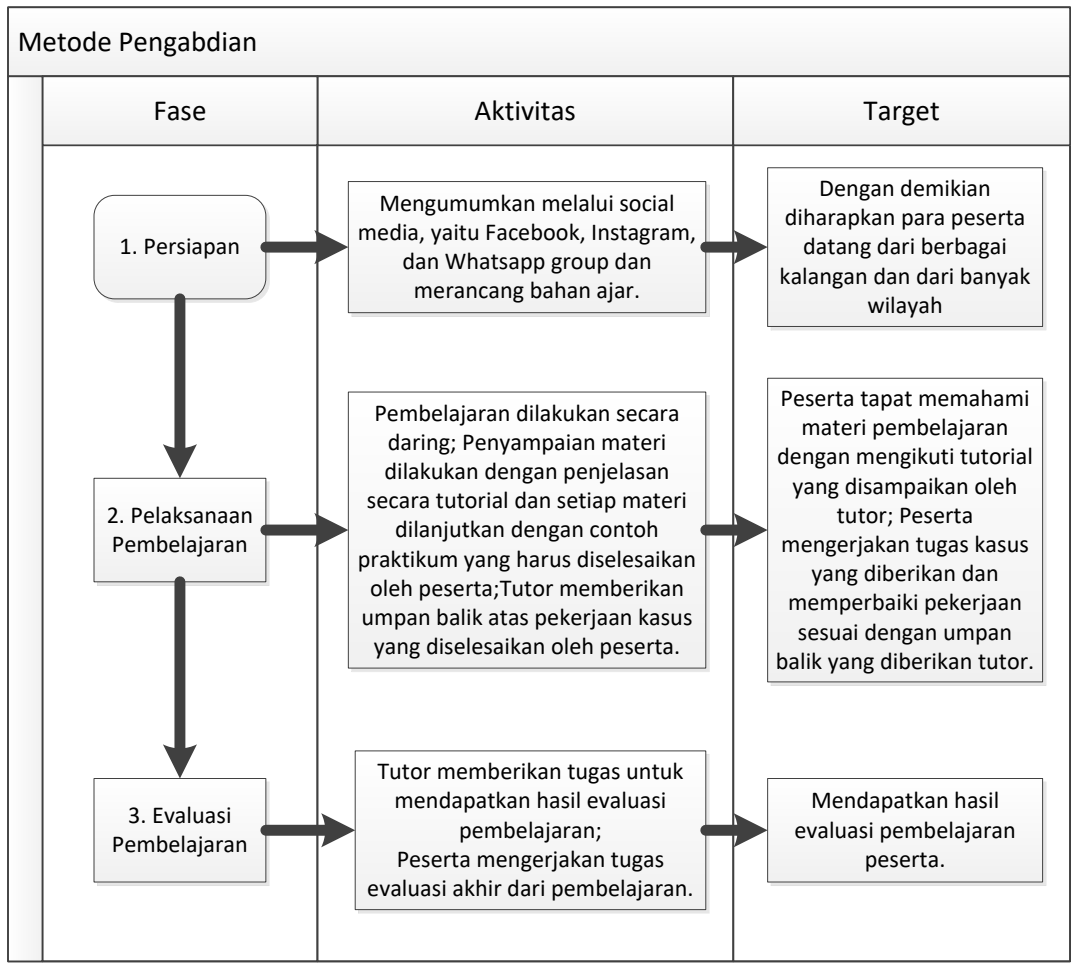

Gambar 1. Metode pengabdian. 
Pembelajaran Jarak Jauh Pemrograman Dasar Menggunakan Bahasa C++ Untuk Umum:

Sebuah Program Pengabdian Kepada Masyarakat

\section{HASIL DAN PEMBAHASAN}

Dalam pelatihan ini digunakan buku pegangan C How TO Program karya Dietel dan Dietel[12] sebagai materi utama dan dikombinasi dengan materi dari referensi lain. Materi yang diajarkan berkaitan dengan pemrograman dasar menggunakan $\mathrm{C}++$ dalam program ini yang dijelaskan pada tabel 1.

Tabel 1. Materi pembelajaran.

\begin{tabular}{|c|c|}
\hline IOPI & \\
\hline $\begin{array}{l}\text { 1. Konsep Dasar } \\
\text { Pemrograman dan } \\
\text { Bahasa } \\
\text { Pemrograman[13] }\end{array}$ & $\begin{array}{l}\text { Pada bagian ini para peserta diberikan penjelasan mengenai konsep } \\
\text { dasar pemrograman dan bahasa pemrograman, jenis-jenis dan contoh } \\
\text { bahasa pemrograman, penjelasan tentang source code (kode sumber), } \\
\text { executable application, compiler, dan linker. }\end{array}$ \\
\hline $\begin{array}{l}\text { 2. Pengenalan Bahasa } \\
\mathrm{C}++[14]\end{array}$ & $\begin{array}{l}\text { Disini dikenalkan tentang level bahasa (tinggi, menengah, dan rendah) } \\
\text { dan level bahasa } \mathrm{C}++ \text {. Selain itu disebutkan dan dijelaskan fitur-fitur } \\
\text { dari bahasa } \mathrm{C}++ \text {. }\end{array}$ \\
\hline $\begin{array}{ll}\text { 3. } & \text { Struktur } \\
\mathrm{C}++[13]\end{array}$ & $\begin{array}{l}\text { Pada bagian ini dijelaskan struktur bahasa C++, library, kaitan antara } \\
\text { function dengan library, dan penggunaan library ke dalam sebuah } \\
\text { program. Kasus: Membuat program sederhana "Hello world" }\end{array}$ \\
\hline 4. $\operatorname{Inp}$ & $\begin{array}{l}\text { Penjelasan mengenai masukan (input) data melalui keyboard (papan } \\
\text { tombol) dan keluaran data di screen (layar monitor). Kasus: Membuat } \\
\text { program untuk menghitung luas dan keliling segitiga, dan luas dan } \\
\text { keliling lingkaran. }\end{array}$ \\
\hline 5. Tip & $\begin{array}{l}\text { Pada bagian ini dijelaskan mengenai tipe data berikut data yang bisa } \\
\text { masuk ke dalam variabel pada setiap tipe data. Disini dijelaskan juga } \\
\text { mengenai operand, operator, dan assignment. }\end{array}$ \\
\hline $\begin{array}{ll}\text { 6. } & \text { Seleksi } \\
& \text { Menggunakan IF[8] }\end{array}$ & $\begin{array}{l}\text { Penjelasan mengenai pemilihan, kondisi dan akibat dari benar } \\
\text { (terpenuhi) dan salah (tidak terpenuhinya) kondisi. Kasus: Membuat } \\
\text { program untuk menghitung persamaan kuadrat, dengan input } \mathrm{a}, \mathrm{b} \text {, dan } \mathrm{c} \\
\text { lalu menghasilkan nilai } \mathrm{x} 1 \text { dan } \mathrm{x} 2 \text {. }\end{array}$ \\
\hline $\begin{array}{l}\text { 7. Perulangan } \\
\text { Menggunakan } \\
\text { FOR[8] }\end{array}$ & $\begin{array}{l}\text { Penjelasan mengenai perulangan menggunakan FOR, kondisi dan } \\
\text { akibat dari benar (terpenuhi) dan salah (tidak terpenuhinya) kondisi. } \\
\text { Kasus: Membuat program untuk memasukkan sejumlah } \mathrm{N} \text { bilangan } \\
\text { (bisa bulat maupun pecahan) lalu dihitung nilai total dari angka-angka } \\
\text { yang dimasukkan, dihitung nilai rata-ratanya, dan dicari nilai terkecil } \\
\text { dan terbesarnya. }\end{array}$ \\
\hline $\begin{array}{l}\text { 8. Perulangan } \\
\text { Menggunakan } \\
\text { WHILE[8] }\end{array}$ & $\begin{array}{l}\text { Penjelasan mengenai perulangan menggunakan WHILE, kondisi dan } \\
\text { akibat dari benar (terpenuhi) dan salah (tidak terpenuhinya) kondisi. } \\
\text { Kasus: Seperti nomor } 7\end{array}$ \\
\hline $\begin{array}{l}\text { 9. Perulangan } \\
\text { Menggunakan } \\
\text { - WHILE[8] }\end{array}$ & $\begin{array}{l}\text { Penjelasan mengenai perulangan menggunakan DO - WHILE, kondisi } \\
\text { dan akibat dari benar (terpenuhi) dan salah (tidak terpenuhinya) } \\
\text { kondisi. Kasus: Seperti nomor } 7\end{array}$ \\
\hline 10. Array[13] & $\begin{array}{l}\text { Penjelasan tipe data majemuk dalam bentuk Array. Menjelaskan indeks } \\
\text { dan cara mengakses data pada setiap elemen di dalam array. Kasus: } \\
\text { Membuat program untuk memasukkan sejumlah } \mathrm{N} \text { bilangan (bisa bulat } \\
\text { maupun pecahan). Setiap bilangan tersebut dimasukkan kedalam } \\
\text { sebuah array. Lalu berdasarkan array tersebut dihitung nilai total dari }\end{array}$ \\
\hline
\end{tabular}




\begin{tabular}{ll}
\hline & angka-angka yang dimasukkan, dihitung nilai rata-ratanya, dan dicari \\
& nilai terkecil dan terbesarnya. \\
\hline 11. String[13] & Penjelasan mengenai string. Kaitan string dengan array. Kasus: \\
& Membuat program untuk memasukkan suatu kalimat. Lalu menghitung \\
& jumlah karakter dalam kalimat tersebut, mendapatkan karakter pertama, \\
& mendapatkan karakter terakhir, menghitung jumlah huruf besar, jumlah \\
& huruf kecil, dan total huruf dalam kalimat tersebut. \\
\hline
\end{tabular}

Kegiatan PkM pelatihan ini dilaksanakan dalam waktu yang cukup panjang yaitu setiap hari Sabtu pukul 10:00 - 11:30 mulai 3 Oktober 2020 sampai dengan 13 Februari 2021. Jumlah pendaftar adalah sebanyak 46 orang peserta. Gambar 2 menampilkan sebaran peserta berdasarkan kota, pendidikan, pekerjaan, dan motivasi mereka mengikuti pelatihan ini. Jumlah peserta yang paling banyak adalah dari Bogor dan Bekasi. Namun demikian ada juga dari berbagai kota di pulang jawa dan 2 orang dari luar Jawa, yaitu masing-masing dari Medan, Sumatera Utara dan Bone, Sulawesi Selatan.

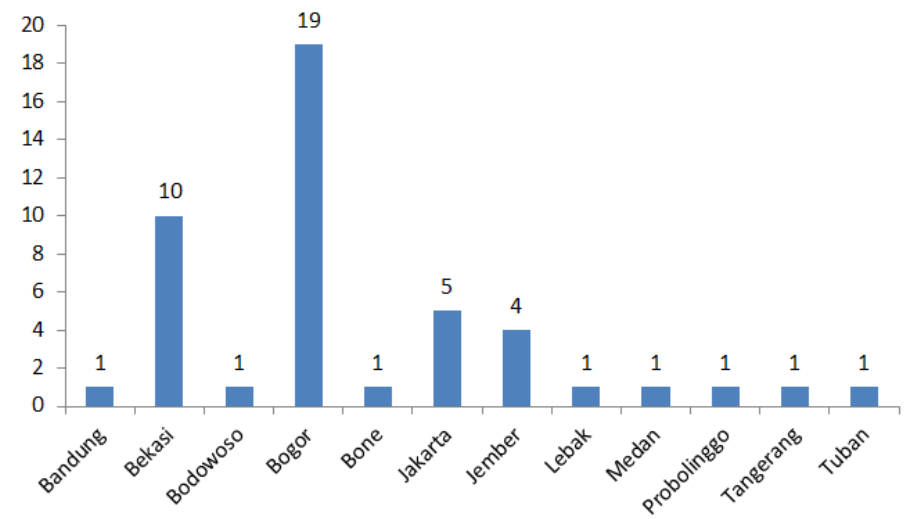

Gambar 2. Sebaran peserta berdasarkan kota.

Berdasarkan jumlah peserta berdasarkan jenjang pendidikan terakhir atau pendidikan yang sedang ditempuh mayoritas peserta adalah sedang kuliah (S1) dan SMA (Sekolah Menengah Atas). Yang menarik dalam analisis peserta berdasarkan pendidikan ternyata ada seorang peserta yang masih dalam pendidikan SD (Sekolah Dasar) dan 2 orang pada jenjang pendidikan SMP (Sekolah Menengah Pertama). Gambaran rinci tampak pada gambar 3.

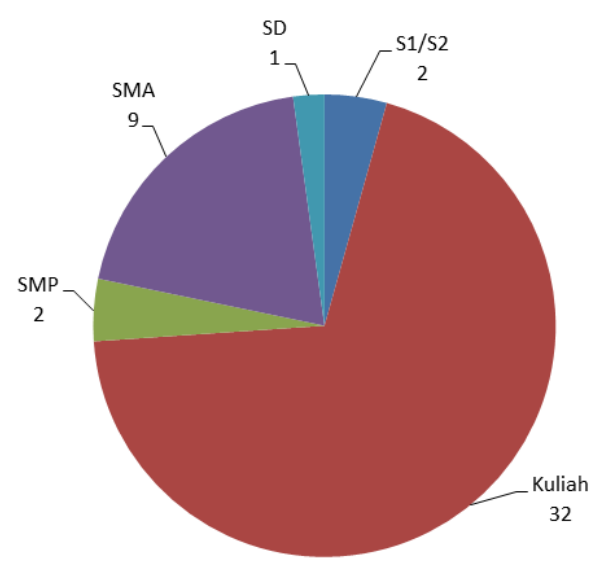

Gambar 1. Sebaran peserta berdasarkan pendidikan

Gambar 4 menjelaskan jumlah peserta berdasarkan pekerjaan. Mayoritas adalah mahasiswa dan disusul pelajar dan karyawan. Uniknya ada 3 orang guru/dosen yang berminat mengikuti pelatihan ini. 
Pembelajaran Jarak Jauh Pemrograman Dasar Menggunakan Bahasa C++ Untuk Umum:

Sebuah Program Pengabdian Kepada Masyarakat

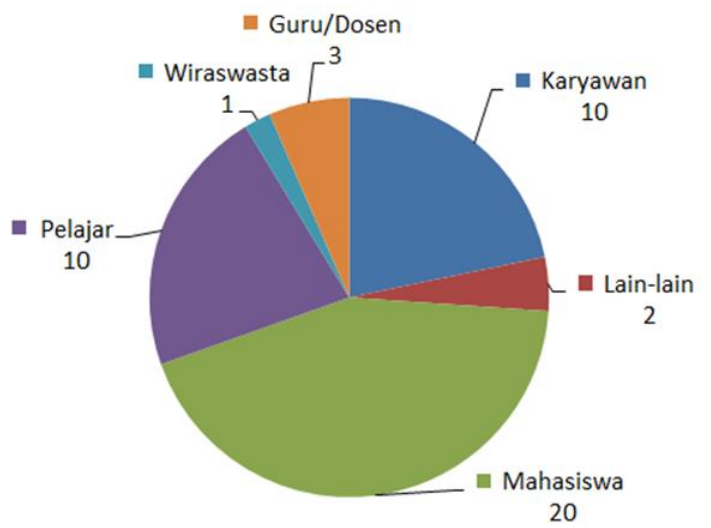

Gambar 4. Sebaran peserta berdasarkan pekerjaan

Sedangkan motivasi para peserta tertarik mengikuti pelatihan pemrograman $\mathrm{C}++$ bermacammacam tetapi umumnya bagi yang belum pernah belajar bahasa pemrograman adalah ingin belajar dan menambah wawasan sedangkan yang sudah pernah belajar bahasa pemrograman mereka ingin memperdalam pengetahuan mereka.

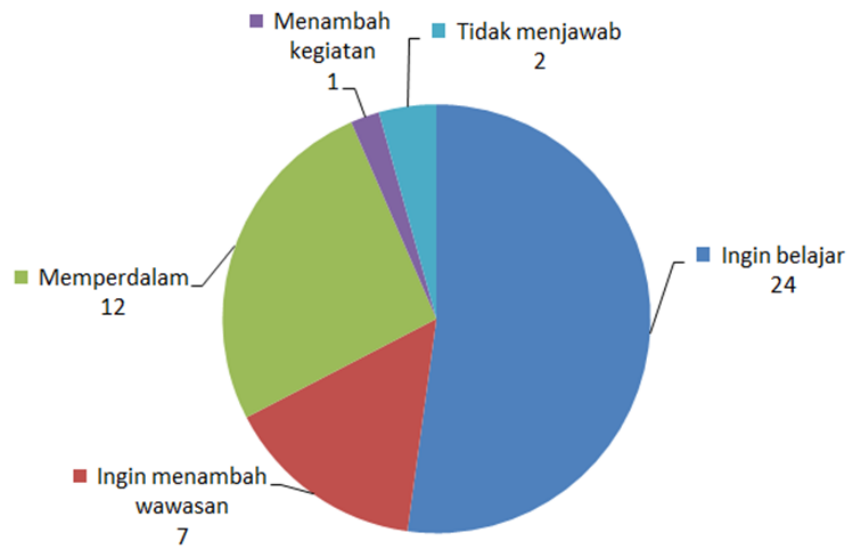

Gambar 5. Sebaran peserta berdasarkan motivasi.

Setelah selesai pembelajaran maka diberikan kuesioner kepada para peserta. Angket ini bertujuan untuk menangkap (1) masalah/kendala yang mereka hadapi selama pelatihan secara daring, (2) apakah pelatihan berjalan dengan baik, (3) apakah mereka tertarik/berminat jika pelatihan yang sama atau pelatihan yang lebih tinggi dilakukan lagi, (4) bagaimana kualitas interaksi pengajar dengan mereka, (5) bagaimana kualitas bahan ajar selama pelatihan, dan (6) apa saja perbaikan yang mereka sarankan untuk pelatihan selanjutnya.

Masalah koneksi internet yang lambat menjadi kendala bagi pembelajaran daring. Sebanyak 43\% dari peserta mengeluhkan hal ini disamping $29 \%$ mengeluhkan masalah waktu yang tidak sesuai dengan mereka mengingat Sabtu pagi adalah waktu bersama keluarga atau bekerja bagi yang bekerja di pagi hari dan mereka menyarankan agar waktu pembelajaran di sore/malam hari. Sementara kendala lainnya adalah pengajar terlalu cepat dalam menjelaskan dan kurang banyak latihan. Secara jelas bisa tampak pada gambar 6. 


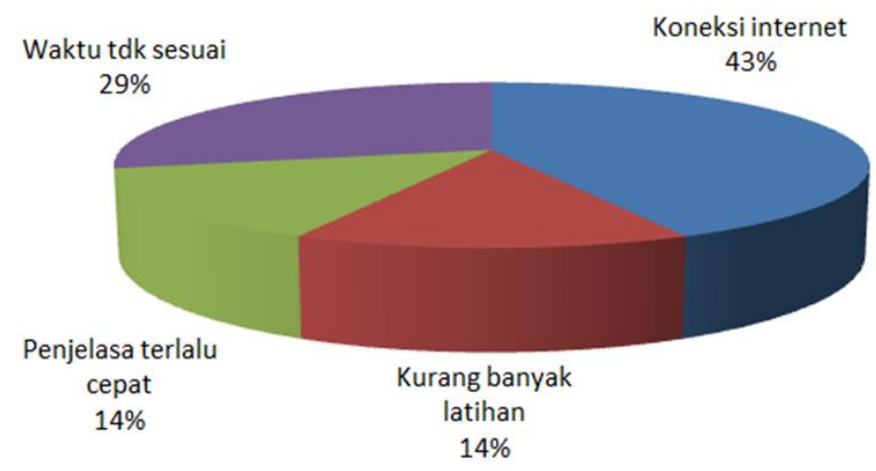

Gambar 6. kendala selama pelatihan.

Berkaitan dengan keadaan pelatihan apakah berjalan dengan baik, maka 71\% menjawab pelatihan berjalan dengan baik sementara sisanya sebesar $29 \%$ menjawab dengan sangat baik. Dengan demikian dapat disimpulkan bahwa pelatihan berjalan dengan baik. Ketika ditawarkan apakah tertarik mengikuti pelatihan yang sama atau pelatihan yang lebih tinggi tingkatannya, 86\% peserta menjawab sangat tertarik dan sisanya menjawab cukup tertarik.

Sementara berkaitan dengan kualitas interaksi peserta dengan pengajar, mayoritas para peserta menyatakan interaksi pengajar dengan para peserta berkualitas. Sebanyak $29 \%$ peserta menjawab sangat baik dan 57\% menjawab baik sebagaimana tampak pada gambar 7 .

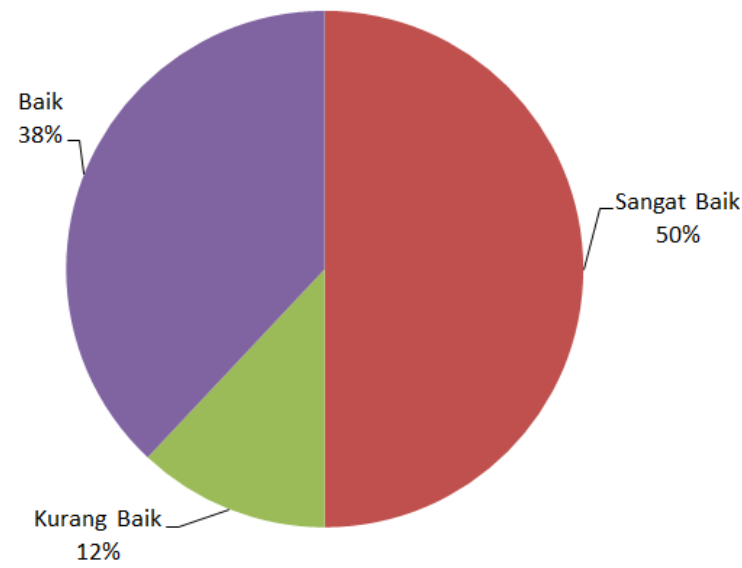

Gambar 7. Kualitas interaksi peserta dengan pengajar.

Begitu juga dengan bahan ajar, mereka menyatakan bahan ajar berkualitas. Sebanyak 57\% menyatakan sangat baik sedangkan sisanya menyatakan baik. Grafik pada gambar 8 menjelaskan hal ini. 
Pembelajaran Jarak Jauh Pemrograman Dasar Menggunakan Bahasa C++ Untuk Umum:

Sebuah Program Pengabdian Kepada Masyarakat

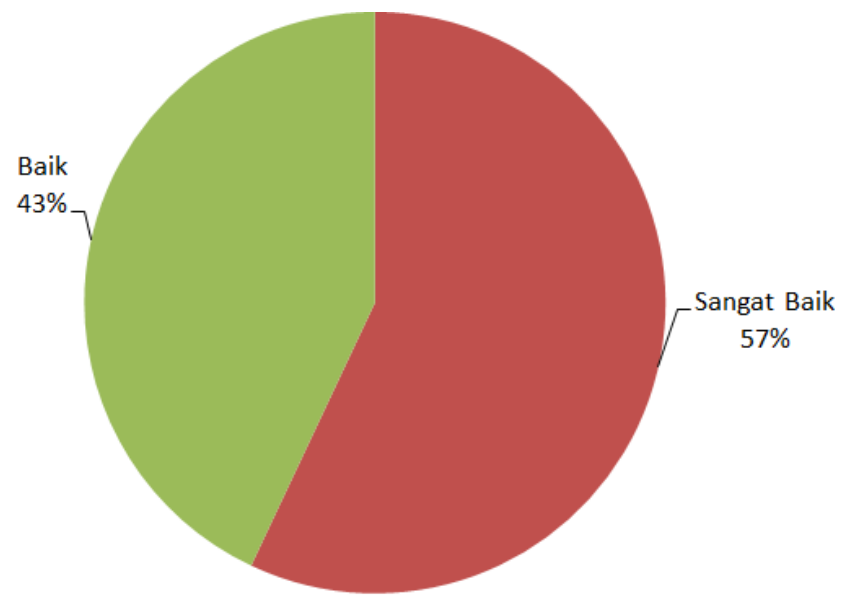

Gambar 8. Kualitas bahan ajar.

Di bagian akhir angket para peserta diminta memberikan saran perbaikan untuk program PkM ini. Dari saran tersebut dirangkum menjadi tiga saran perbaikan untuk kegiatan yang sama di masa yang akan datang.

- Memperbanyak latihan-latihan pada setiap materi.

- Lebih banyak mengulang materi yang sudah diajarkan dan kalau sudah mengerti semua baru membahas pelajaran selanjutnya.

- Pembahasan materi menggunakan perumpamaan yang ringan dan umum agar dapat lebih mudah untuk dipahami seluruh peserta pelatihan.

Dari sejumlah peserta tersebut yang mengikuti pembelajaran sampai akhir terdapat 5 (lima) orang peserta yang paling menonjol dan paling berminat besar dalam pembelajaran ini. Yaitu, 3 (tiga) orang peserta kelas 1 peserta SMA, 1 (satu) orang peserta kelas 2 SMP, dan 1 (satu) orang mahasiswa. Mereka menyatakan bahwa materi pembelajaran yang mereka terima selama diajar pemrograman dasar dengan bahasa $\mathrm{C}++$ sangat bisa mereka pahami dan dapat mereka jadikan dasar untuk belajar bahasa pemrograman yang lain atau bahasa yang sama tetapi dengan materi yang lebih tinggi dan kasus yang lebih rumit. Sesuatu yang membanggakan dari program ini adalah salah satu dari 2 (orang) peserta yang duduk di bangku kelas 1 SMA telah berhasil terpilih untuk menjadi peserta olimpiade komputer nasional di sekolahnya. Salah satunya karena dia serius mengikuti dan serius berlatih dalam program ini.

\section{SIMPULAN}

Pelatihan pemrograman dasar menggunakan bahasa pemrograman $\mathrm{C}++$ sangat diminati oleh kalangan umum. Mereka yang mengikuti program ini merasakan manfaat dari program ini dan menginginkan agar pelatihan yang sama atau dengan topik yang lebih tinggi dilaksanakan lagi di kemudian hari. Untuk itu program ini perlu dilanjutkan dengan perbaikan-perbaikan untuk meningkatkan kualitas pembelajaran dan memberikan hasil yang lebih baik. Karena para peserta kebanyakan belum pernah mengenal pemrograman maka inovasi dan kreativitas dalam penyajian materi menjadi hal penting agar mereka semakin tertarik dan paham materi yang disampaikan.

\section{UCAPAN TERIMA KASIH}

Pada kesempatan ini tim penulis mengucapkan terima kasih kepada tim dari Keysoft Academy yang telah mengorganisir dan membantu pelaksanaan program ini. Terima kasih terutama kepada Saudara Ivan Rifki Nur Alif dan Saudara Ikhsan Hussien.

\section{DAFTAR PUSTAKA}

[1] A. Sistarina, "Implementasi Literasi Informasi Sebagai Upaya Perpustakaan Universitas 
Airlangga Mendukung Tri Dharma Perguruan Tinggi," JPUA J. Perpust. Univ. Airlangga Media Inf. dan Komun. Kepustakawanan, vol. 10, no. 2, p. 104, 2020, doi: 10.20473/jpua.v10i2.2020.104-115.

[2] M Anas Sobarnas, Mustopa Idris, Nurkholis, and Ashari Imamuddin, "Manajemen Pengelolaan Website Dalam Rangka Pemberdayaan Pelajar Sekolah Menengah Kejuruan Muhammadiyah 2 Cileungsi," BEMAS J. Bermasyarakat, vol. 1, no. 1, pp. 1-8, 2020, doi: 10.37373/bemas.v1i1.48.

[3] A. Imamuddin, "An Enterprise Resource Planning System Solution for Small-Mid Size Enterprises: An Information System Development Case Study," J. Comput. Sci. Inf. Technol. Telecommun. Eng., vol. 2, no. 1, pp. 160-168, 2021, doi: 10.30596/jcositte.v2i1.6534.

[4] A. Saputra, A. Imamuddin, and P. Sukamto, "Rancang Bangun Aplikasi Sistem Penjualan Case Study: Pt. X," INFOTECH J. Inform. Teknol., vol. 1, no. 2, pp. 78-86, 2020, doi: 10.37373/infotech.v1i2.67.

[5] S. Nugroho, M. A. Pahmi, and A. Surya, "Lokakarya Penguatan Kualitas Sumber Daya Manusia Generasi Muda Dalam Menghadapi Era Industrialisasi," Bermasyarakat, vol. 1, no. 1, pp. 39-50, 2020.

[6] S. A. Prabowo, Wilarso, and A. Saepudin, "PROGRAM PkM OPTIMALISASI WAKTU PEMROGRAMAN PADA PERANGKAT LUNAK TRUTOPS V 1.2.1 DI PT. UVW," vol. 1, no. September, pp. 15-24, 2020.

[7] A. Imamuddin, I. Nahar, and S. Chandra, "TransJoin: An Algorithm to Implement Division Operator of Relational Algebra in Structured Query Language," in Journal of Physics: Conference Series, 2020, doi: 10.1088/1742-6596/1477/3/032003.

[8] H. Mohapatra, C Programming: Practice, no. May. Apress, 2020.

[9] A. Imamuddin, "An Integrated Information System Design for Managing National Hazardous Waste in Indonesia: A Proposal," An Integr. Inf. Syst. Des. Manag. Natl. Hazard. Waste Indones. A Propos., vol. 2, no. 1, pp. 158-164, 2021.

[10] P. R. Indonesia, Undang-undang Republik Indonesia Nomor 20 Tahun 2003 Tentang Sistem Pendidikan Nasional. Indonesia, 2003.

[11] A. Imamuddin, "Rancangan Database Storage Engine Menggunakan Data Dalam Format Xml,” J. Fak. Huk. UII, vol. 2007, no. Snati, 2007, [Online]. Available: https://journal.uii.ac.id/Snati/article/viewFile/1688/1470.

[12] P. J. Deitel and H. M. Deitel, $C$ How to Program with an introduction to $C++8$ th Edition Global Edition, 8th Editio. Pearson Education, Inc., 2016.

[13] N. Kalicharan, Learn to Program with C Learn to Program using the Popular Learn to Program. Apress, 2015.

[14] R. T. Sataloff, M. M. Johns, and K. M. Kost, "C and C++ Compiling."

[15] N. Singh, "Fundamentals of C Programming Dr . Nilu Singh School of Computer Applications Lucknow-UP," no. July, 2020.

[16] Tutorials Point, "Learning C Programming," p. 17, 2014, [Online]. Available: https://www.tutorialspoint.com/cprogramming/cprogramming_tutorial.pdf. 